\title{
The Use of Dehydrated Amniotic Membrane Allograft for the Augmentation of Dural Repair in Craniotomies
}

\author{
Daniel G. Eichberg ${ }^{1}$, Sheikh C. Ali ${ }^{2}$, Simon S. Buttrick ${ }^{3}$, Ricardo J. Komotar ${ }^{1}$ \\ 1. Neurological Surgery, University of Miami Miller School of Medicine, Miami, USA 2. College of Osteopathic \\ Medicine, Nova Southeastern University, Fort Lauderdale, USA 3. Neurological Surgery, University of Miami Miller \\ School of Medicine, Miami, USA
}

Corresponding author: Daniel G. Eichberg, deichberg35@gmail.com

\begin{abstract}
Background: In cranial neurosurgery, primary watertight dural closure is the standard method of postcraniotomy dural repair. However, cerebrospinal fluid (CSF) leaks, pseudomeningoceles, postoperative infections, and dural scarring are possible complications, even when a meticulous technique is implemented. For this reason, materials that enhance the dura's ability to create a watertight seal, inhibit the inflammatory response, and prevent disease transmission are sought. Dehydrated amniotic membrane (DAM) allograft appears to facilitate these properties, as studies have shown that it improves wound healing, prevents scar tissue formation, promotes epithelialization, and inhibits bacterial growth. We detail the use of a DAM allograft to augment dural closures for craniotomies.
\end{abstract}

Methods: We conducted a pilot study, retrospectively reviewing our institution's database of craniotomies that utilized DAM to supplement dural closure.

Results: A total of 122 cases, including 18 initial craniotomies for infratentorial lesions, 102 initial craniotomies for supratentorial lesions, one re-do craniotomy for supratentorial recurrent glioma, and one craniotomy for an anterior skull base schwannoma used a DAM allograft to augment dural closure. Only one complication occurred ( $0.8 \%$ complication rate), which was a superficial wound infection requiring washout without craniectomy. No CSF leaks occurred.

Conclusions: This pilot study demonstrates that dehydrated amniotic membrane allograft can be safely utilized as an adjunct during dural closures for craniotomies.

Received 05/02/2018

Review began 05/02/2018 Review ended 05/04/2018 Published 05/07/2018

๑) Copyright 2018 Eichberg et al. This is an open access article distributed under the terms of the Creative Commons Attribution License CC-BY 3.0., which permits unrestricted use, distribution, and reproduction in any medium, provided the original author and source are credited.
Categories: Neurosurgery

Keywords: brain tumor, cerebrospinal fluid leak, cerebrospinal fluid leak, craniotomy, dehydrated amniotic membrane, dural repair, neurosurgery

\section{Introduction}

After craniotomy with a dural opening, sutured watertight dural repair is the preferred method of closure, as it is believed to minimize the risk of cerebrospinal fluid (CSF) leakage and infection. However, tissue loss or dural compromise can make this technique unfeasible, especially in cases of prior radiation or revision craniotomy. Further, even when the ideal dural closure technique is employed, postoperative complications, such as CSF leaks, meningitis, abscesses, pseudomeningoceles, and dural scarring, may occur, possibly due to holes made in the dura by the suture needle [1].

When a primary dural closure is not possible, neurosurgeons must repair the dura with a dural reinforcement material or substitute, such as an allograft, xenograft, or synthetic biomaterial, each with their respective drawbacks [2]. Autologous tissues, such as pericranium, temporal fascia, and fascia lata, avoid the risk of disease transmission and an immunologic rejection. However, harvesting these tissues increases surgical invasiveness, which may increase the overall risk of local tissue damage, infection, or pain. Dural allografts, such as lyophilized cadaveric human dura mater, are not routinely used in cranial neurosurgery since cases have been reported demonstrating the transmission of prion diseases, such as Creutzfeldt-Jakob disease [2-4]. Synthetic biomaterials have largely been abandoned due to the excessive generation of an inflammatory reaction resulting in underlying brain irritation, meningitis, hemorrhage, graft encapsulation, and inordinate scar formation [5-7]. Thus, there is great demand for a dural augmentation material that does not generate an inflammatory or fibrotic scar response, creates a watertight seal, and does not transmit disease.

Dehydrated amniotic membrane (DAM) has been shown to inhibit fibrosis and scar formation, prevent an immune response, promote epithelization, and have antibacterial and anti-inflammatory properties [8]; thus, it may be an ideal dural substitute. DAM has been successfully utilized in wound closure in multiple 


\section{Cureus}

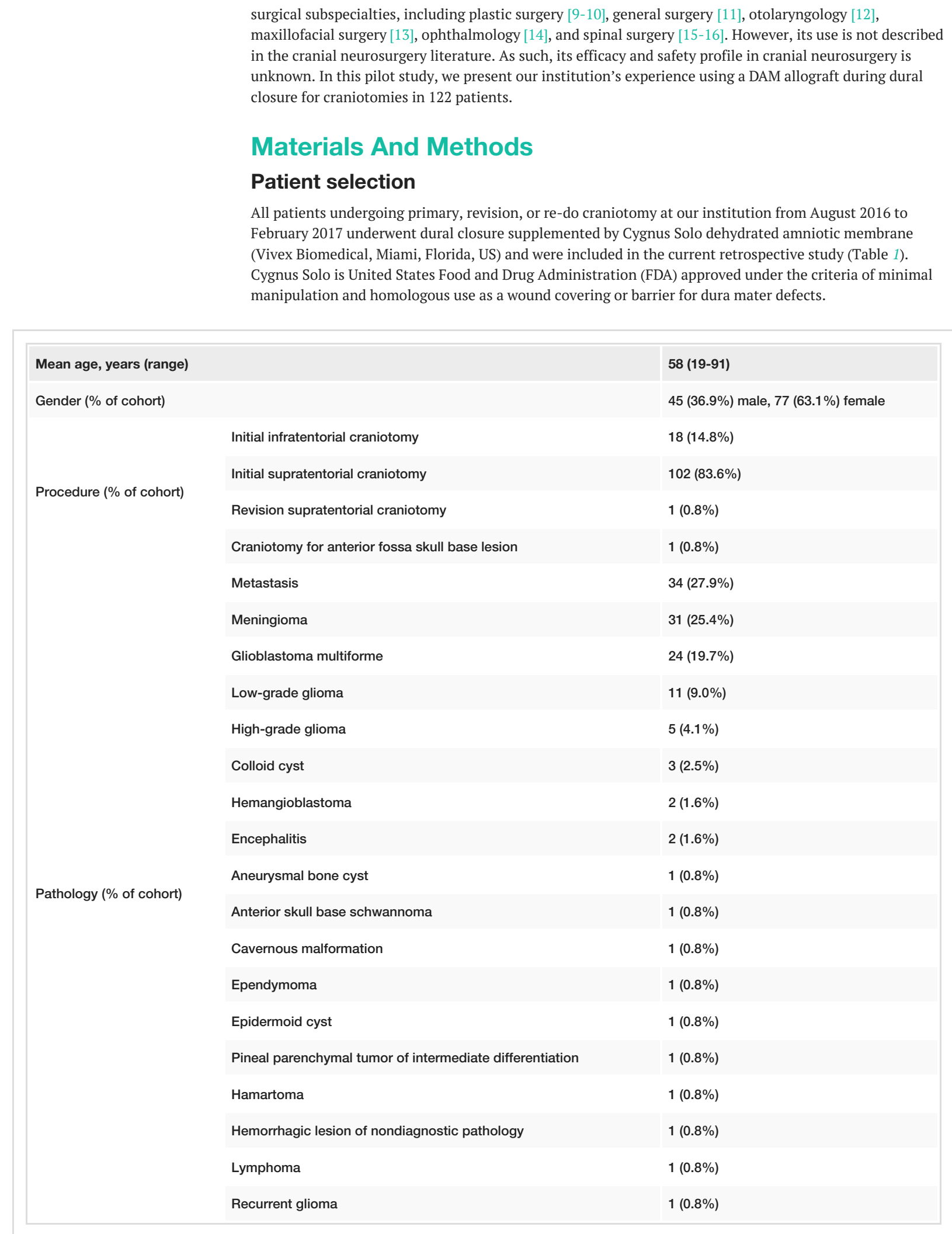

TABLE 1: Summary of patients' demographic characteristics

The senior neurosurgeon's (RJK) clinical database was searched to obtain all relevant patients, and the electronic medical record was analyzed to determine patient demographic data, operative information, and post-operative course. Institutional review board (IRB) approval was obtained before proceeding with clinical database review (IRB \# 20170675), along with a waiver of informed consent. 


\section{Cureus}

\section{DAM layering technique}

Watertight dural closure using running 4-0 braided nylon suture is attempted in all cases. If this cannot be achieved, the dura is approximated with interrupted sutures to create a scaffold for the dural substitute. Next, a layer of DAM is placed over the dura, epithelial side up. Afterward, a sheet of a bovine collagen dural substitute (Duragen, Integra LifeSciences, Plainsboro, New Jersey, US) is placed over the DAM. Finally, the bone flap is secured in place with titanium plates and screws, followed by skin closure with sutures.

\section{Results}

A total of 122 cases (Table 1) using DAM allografts was performed at our institution from August 2016 to February 2017 by the senior neurosurgeon (RJK). Table 1 shows a summary of patient demographics. The average patient age was 58.0 years. Forty-five patients (36.9\%) were male and 77 (63.1\%) were female.

Eighteen (14.8\%) initial craniotomies for infratentorial lesions, 102 (83.6\%) initial craniotomies for supratentorial lesions, one $(0.8 \%)$ revision craniotomy for a supratentorial recurrent glioma, and one $(0.8 \%)$ initial supratentorial craniotomy for an anterior skull base schwannoma used a DAM allograft to supplement dural closure. The three most common pathologies included metastases, meningiomas, and glioblastoma multiforme.

One postoperative complication occurred, which consisted of a superficial wound infection requiring washout without craniectomy (Table 2). No cases were complicated by a CSF leak. No revision craniotomies were complicated by a postoperative wound infection or CSF leak.

\begin{tabular}{|c|c|c|c|}
\hline & Number of cases (\%) & Wound infections (\%) & CSF leaks (\%) \\
\hline Initial craniotomy for infratentorial lesion & $18(14.8 \%)$ & $1(1.0 \%)$ & 0 \\
\hline Initial craniotomy for supratentorial lesion (non-skull base) & $102(83.6 \%)$ & 0 & 0 \\
\hline Revision craniotomy for supratentorial lesion (non-skull base) & $1(0.8 \%)$ & 0 & 0 \\
\hline Craniotomy for anterior skull base schwannoma & $1(0.8 \%)$ & 0 & 0 \\
\hline All cases & $122(100 \%)$ & $1(0.8 \%)$ & 0 \\
\hline
\end{tabular}

\section{TABLE 2: Complication rates}

Abbreviation: CSF: cerebrospinal fluid

After bone flap removal in the case of the revision craniotomy for recurrent glioma, the DAM previously placed during the closure of the original craniotomy for tumor resection was seen intact and fully integrated into the surrounding dura.

\section{Discussion}

The standard technique for dural repair after the completion of craniotomy is a sutured, watertight closure. However, watertight closure is not always feasible, especially for convexity meningiomas where the dura has been purposefully removed, and in cases of prior surgery or prior radiation exposure, in which the dural integrity is compromised. Additionally, even when a watertight dural closure is achieved and confirmed by an intraoperative Valsalva maneuver, postoperative CSF leak, pseudomeningocele, infection, and dural scarring may occur [1]. Therefore, a dural augmentation material that reduces the rates of these complications is desirable.

Ideally, a dural supplementation material should promote epithelization to integrate with the native dura but not allow for adhesions to form to the underlying brain. Additionally, it should be immunologically inert to minimize the risk of inflammation, scarring, and immunologic rejection. Finally, the optimal dural adjunct is sterile to minimize the risk of pathogenic transmission and non-toxic to avoid local tissue damage [2]. A dehydrated amniotic membrane (DAM) may confer all of these characteristics.

Because it lacks numerous cell surface antigens that generate an immunologic response, DAM is considered to be a non-immunogenic material and, therefore, does not trigger a graft rejection reaction [17-18]. Amniotic epithelial cells have also been demonstrated to have anti-inflammatory properties $[8,19]$. Additionally, amniotic tissue has been shown to inhibit bacterial growth and have antimicrobial properties [20-22]. 
Further, DAM is known to reduce fibrosis due to the presence of numerous growth factors, which are responsible for the proliferation, migration, and differentiation of epithelial cells and epithelialization. For this reason, fetuses have been shown to heal wounds without forming scars [23]. This anti-scar formation property has popularized DAM in burn repair and plastic surgery applications [9-10]. If a revision surgery is needed, postoperative dural scar formation from the initial surgery may complicate dural reopening if the dura is adherent to the brain due to scar formation. Additionally, prior scar formation may complicate the reclosure of the dura, potentially increasing the risk of post-operative infection and CSF leaks. For these reasons, the postoperative risk of dural scar formation is ideally minimized. Our experience with DAM appears to be consistent with the reported findings of decreased postoperative scar formation. In the case of a re-operative craniotomy for a recurrent glioma, we report that DAM previously placed during the original craniotomy was found intact and fully integrated into the surrounding dura, with minimal fibrosis or scar tissue.

Successful DAM use has been described in numerous non-neurosurgical clinical applications, such as corneal repair, burn treatment, and oral cavity reconstruction [8-13]. In neurosurgery, autologously harvested amniotic membrane has been used to repair dural defects in myelomeningocele [16].

Although the human cranial neurosurgery applications of DAM have not been thoroughly investigated, an in vivo rat cranial surgery model demonstrated that human xenograft DAM was efficacious and had an adequate safety profile. Tomita et al. (2012) developed a rat model in which 20 rats underwent a skull base craniotomy with the excision of dura and the placement of dehydrated human amniotic membrane [2]. None of the cases experienced clinical adverse reactions related to the DAM or CSF leak. Interestingly, on a histological examination at six months postoperatively, the dehydrated human amniotic membrane was completely resorbed and replaced with a rat-derived membranous structure.

Published infection rates for craniotomies vary widely; a recent matched case-control study of 2819 patients described a postoperative infection rate of $2.47 \%$ [24]. Our series' postoperative infection rate of $0.8 \%$ is comparable to that of reported infection rates, suggesting that DAM does not increase the postoperative infection rate. Similarly, the reported rates of postoperative CSF leaks differ among studies and craniotomy locations; leaks may complicate between $4 \%$ and $17 \%$ of craniotomies for posterior fossa lesions [25]. In our series of 122 craniotomies, including 18 craniotomies for posterior fossa lesions, none were complicated by postoperative CSF leaks. These results suggest that DAM does not contribute to the increased risk of CSF leaks.

Because re-operative craniotomies are considered a higher risk for a postoperative CSF leak or infection, the finding that our reported case of a re-operative craniotomy for a recurrent tumor in our series had no postoperative complications provides further evidence to the claim that DAM is a promising dural supplement for the closure of craniotomies.

Our pilot study is limited by the fact that it has no control group that used closure without DAM or with other dural adjuncts, and it was not randomized. While our reported infection rates and CSF leak rates were comparable to or lower than previously reported rates [24-25] because the study was not randomized, the findings could be biased due to confounding variables. Further, the interpretation of the data is complicated by the fact that the patients in our study received a sheet of bovine collagen dural substitute layered on top of the DAM; thus, the outcomes may be due to both materials. Future studies with patients randomized into groups with other dural closure techniques are required to validate our study.

While this retrospective pilot study does not prove the superiority of DAM over other dural adjuncts, or the efficacy of use, we demonstrate that it has an adequate safety profile with no complications directly related to its use in closures for craniotomies. We also report very low CSF leak rates and infection rates, particularly in craniotomies for infratentorial lesions. Future randomized controlled studies are warranted to determine the safety profile and efficacy in comparison to other closure techniques and dural adjuncts.

\section{Conclusions}

We report the use of a dehydrated amniotic membrane (DAM) allograft during the closure of craniotomies. With this pilot study, we report an adequate safety profile with no adverse reactions directly related to the DAM product. Future studies are warranted that compare DAM with other closure techniques and dural supplements to prove efficacy.

\section{Additional Information \\ Disclosures}

Human subjects: Consent was obtained by all participants in this study. University of Miami Institutional Review Board issued approval 20170675. This research was approved by the University of Miami Institutional Review Board with a waiver of informed consent. Animal subjects: All authors have confirmed that this study did not involve animal subjects or tissue. Conflicts of interest: In compliance with the ICMJE uniform disclosure form, all authors declare the following: Payment/services info: All authors have declared that no 
financial support was received from any organization for the submitted work. Financial relationships: All authors have declared that they have no financial relationships at present or within the previous three years with any organizations that might have an interest in the submitted work. Other relationships: All authors have declared that there are no other relationships or activities that could appear to have influenced the submitted work.

\section{Acknowledgements}

The authors would like to thank Linda Alberga for manuscript preparation.

\section{References}

1. Cosgrove GR, Delashaw JB, Grotenhuis JA, et al.: Safety and efficacy of a novel polyethylene glycol hydrogel sealant for watertight dural repair. J Neurosurg. 2007, 106:52-58. 10.3171/jns.2007.106.1.52

2. Tomita T, Hayashi N, Okabe M, Yoshida T, Hamada H, Endo S, Nikaido T: New dried human amniotic membrane is useful as a substitute for dural repair after skull base surgery. J Neurol Surg B Skull Base. 2012, 73:302-307. 10.1055/s-0032-1321506

3. Thadani V, Penar PL, Partington J, et al.: Creutzfeldt-Jakob disease probably acquired from a cadaveric dura mater graft. Case report. J Neurosurg. 1988, 69:766-769. 10.3171/ins.1988.69.5.0766

4. Masullo C, Pocchiari M, Macchi G, Alema G, Piazza G, Panzera MA: Transmission of Creutzfeldt-Jakob disease by dural cadaveric graft [Article in Japanese]. J Neurosurg. 1989, 71:954-955.

5. Thompson DN, Taylor WF, Hayward RD: Silastic dural substitute: experience of its use in spinal and foramen magnum surgery. Br J Neurosurg. 1994, 8:157-167. 10.3109/02688699409027962

6. Simpson D, Robson A: Recurrent subarachnoid bleeding in association with dural substitute. Report of three cases. J Neurosurg. 1984, 60:408-409. 10.3171/jns.1984.60.2.0408

7. Cohen AR, Aleksic S, Ransohoff J: Inflammatory reaction to synthetic dural substitute. Case report. J Neurosurg. 1989, 70:633-635. 10.3171/jns.1989.70.4.0633

8. Fairbairn NG, Randolph MA, Redmond RW: The clinical applications of human amnion in plastic surgery . I Plast Reconstr Aesthet Surg. 2014, 67:662-675. 10.1016/j.bjps.2014.01.031

9. Chuntrasakul C: Clinical experiences with the use of amniotic membranes as temporary dressing treatment of burns and other surgical open wounds. J Med Assoc Thai. 1977, 60:66-71.

10. Colocho G, Graham WP 3rd, Greene AE, Matheson DW, Lynch D: Human amniotic membrane as a physiologic wound dressing. Arch Surg. 1974, 109:370-373. 10.1001/archsurg.1974.01360030022006

11. Erdener A, Ulman I, Ilhan H, Soydan S: Amniotic membrane wrapping: an alternative method to the splenorrhaphy in the injured spleen [Article in English, German]. Eur J Pediatr Surg. 1992, 2:26-28. $10.1055 /$ s-2008-1063394

12. Lyons GD, Dyer RF, Ruby JR: Morphologic analysis of tympanic membrane grafts. Laryngoscope. 1977, 87:1705-1709. 10.1288/00005537-197710000-00015

13. Lawson VG: Pectoralis major muscle flap with amnion in oral cavity reconstruction. Aust N Z J Surg. 1986, 56:163-166.

14. Hanada K, Shimazaki J, Shimmura S, Tsubota K: Multilayered amniotic membrane transplantation for severe ulceration of the cornea and sclera. Am J Ophthalmol. 2001, 131:324-331. 10.1016/S0002-9394(00)00825-4

15. Subach BR, Copay AG: The use of a dehydrated amnion/chorion membrane allograft in patients who subsequently undergo reexploration after posterior lumbar instrumentation. Adv Orthop. 2015, 2015:501202. 10.1155/2015/501202

16. Hasegawa M, Fujisawa H, Hayashi Y, Yamashita J: Autologous amnion graft for repair of myelomeningocele: technical note and clinical implication. J Clin Neurosci. 2004, 11:408-411. 10.1016/j.jocn.2003.11.006

17. Adinolfi M, Akle CA, McColl I, et al.: Expression of HLA antigens, beta 2-microglobulin and enzymes by human amniotic epithelial cells. Nature. 1982, 295:325-327. 10.1038/295325a0

18. Bilic G, Zeisberger SM, Mallik AS, Zimmermann R, Zisch AH: Comparative characterization of cultured human term amnion epithelial and mesenchymal stromal cells for application in cell therapy. Cell Transplant. 2008, 17:955-968. 10.3727/096368908786576507

19. Hao Y, Ma DH, Hwang DG, Kim WS, Zhang F: Identification of antiangiogenic and antiinflammatory proteins in human amniotic membrane. Cornea. 2000, 19:348-352. 10.1097/00003226-200005000-00018

20. Kjaergaard N, Hein M, Hyttel L, Helmig RB, Schonheyder HC, Uldbjerg N, Madsen H: Antibacterial properties of human amnion and chorion in vitro. Eur J Obstet Gynecol Reprod Biol. 2001, 94:224-229. 10.1016/S0301-2115(00)00345-6

21. Thadepalli H, Bach VT, Davidson EC Jr: Antimicrobial effect of amniotic fluid. Obstet Gynecol. 1978, 52:198204.

22. Buhimschi IA, Jabr M, Buhimschi CS, Petkova AP, Weiner CP, Saed GM: The novel antimicrobial peptide beta3-defensin is produced by the amnion: a possible role of the fetal membranes in innate immunity of the amniotic cavity. Am J Obstet Gynecol. 2004, 191:1678-1687. 10.1016/j.ajog.2004.03.081

23. Koizumi NJ, Inatomi TJ, Sotozono CJ, Fullwood NJ, Quantock AJ, Kinoshita S: Growth factor mRNA and protein in preserved human amniotic membrane. Curr Eye Res. 2000, 20:173-177. 10.1076/02713683(200003)2031-9FT173

24. Schipmann S, Akalin E, Doods J, Ewelt C, Stummer W, Suero Molina E: When the infection hits the wound: matched case-control study in a neurosurgical patient collective including systematic literature review and risk factors analysis. World Neurosurg. 2016, 95:178-189. 10.1016/j.wneu.2016.07.093

25. Than KD, Baird CJ, Olivi A: Polyethylene glycol hydrogel dural sealant may reduce incisional cerebrospinal fluid leak after posterior fossa surgery. Neurosurgery. 2008, 63:182-186. 